\title{
Tourism Development of the Cultural Heritage of the Water Conservancy Project from the Nostalgia perspective: Evidence from Baotun Village
}

\author{
Baiping Zhang \\ Central University of Finance and Economics \\ 39 Xueyuannan Rd,Beijing,100081,China \\ Dr.Ying Peng \\ Tourism Department of Anshun College \\ 25 Xueyuan Rd,Anshun,Guizhou,561000 China
}

\begin{abstract}
The cultural heritage of the water conservancy project of the Ming Dynasty in Baotun, Anshun city, Guizhou Province, China was rewarded Excellence of 2011 UNESCO Asia-Pacific Heritage Award for Culture Heritage Conservancy, which set up a remarkable example of agricultural scenery preservation in China. Taking the water conservancy project in Baotun, Anshun city, Guizhou Province for example, the paper aims to make a detailed plan on its tourism development of the cultural heritage areas based on the satisfying the modern people's psychological needs in their inner heart. The authors also hope to promote the protection and sustainable utilization of the ancient water conservancy project and to create a temporal homeland for the modern people to inhabit romantically when they are visiting the rural cultural heritage sites.
\end{abstract}

Keywords: Nostalgia Feelings, Rural Cultural Heritage, the Water Conservancy Project in Baotun

\section{Introduction}

Far away from the nature and the countryside, those living in the modern city have to adapt to the modernism. They begin to feel deeply attached to the traditional society from time to time, which is called "nostalgia" by Heidegger. When occasionally the modern people put themselves in the traditional countryside and they experience something nostalgic, which are the feelings absent in the modern city life. At this time, they do not feel loneliness or isolation any more. In this situation, the rural cultural heritage becomes an important humanity tourist resource for the modern people nowadays. Therefore, it spires an idea of the protection of the rural cultural heritage. The water conservancy project in Baotun (or Baojiatun, the same below), Anshun city, Guizhou Province is the right example in case. It is the symbol of the Tunpu culture, for its construction and improvement embodies the formation of their culture. The sustainable utilization of the project reflects the core values of the Tunpu culture — the social relationship of the clan system, the lifestyle of traditional countryside, the management system of public affairs in the place of Tunpu village. The core values embodied by the water project exactly satisfy the modern people's long desire for the lifestyle in the traditional society and for diverting themselves from sentimentality of nostalgia. It is the nostalgic feelings of the modern people that we can take as a starting point to develop the rural cultural heritage tourism, and to make a connection between tradition and modernity. Therefore, by taking the water conservancy project in Baotun, Anshun city, Guizhou Province for example, the paper aims to make a detailed plan on its tourism development of the cultural heritage areas based on the satisfying the modern people's psychological needs in their inner heart. The author also hopes to promote the protection and sustainable utilization of the water project and to create a temporal homeland for the modern people to inhabit romantically when they are visiting those rural cultural heritages.

\section{The Water Conservancy Project in Baotun}

Baotun is a well-known ancient village where the water conservancy project of the Ming Dynasty was once conferred to the "Award of Excellence" by NUESCO Asia-Pacific Heritage Commission in Bangkok in 2011. This is the highest annual award in the field of Asia -Pacific Heritage Protection. The commission made the following comments on the water project: The preservation project of the watermill in the village of Baojiatun set up an example of agriculture landscape preservation in China. All organizations responsible for different parts of the preservation project cooperated creatively, each of them paying much attention and making much effort to the integration of the base of project. The preservation project restored the former condition of the water facilities, of which the watermill in Baojiatun village is the typical representative with the history of 600 years, revived the producing order of farming through comprehensive recovery of the dams, channels, embankments and watermill. The project also revived their authentic features sensitively and thoughtfully. 
It revived the glory of history. By the integration of the sustainable exploitation of traditional agricultural facilities and local cultural activities, it demonstrated the importance of preserving those rapidly disappearing cultural landscapes in Asia under the pressure of modernization.

The water conservancy project in Baotun is a complete project system. Its water comes from Xingjiang river-- the branch of Wujiang river. At the mouth of the canal, the ancestors in Baotun built a head of canal called Yimaba, where the river was divided into two streams: one was the old river, the other was the new one. They are the main channels of the water project. There are three water sumps, a front-door pond. There are sub-dams allocating water to the lower channels and irrigating the farmland with different heights. People use the fall of river and the topographic condition to build watermills so that the villager can mill rice easily. It is a reutilization of the ancient water project, which has been bringing a great number of benefits for Baotun people and people around the villages. In the years of 2008, 2009 and 2010, lots of places in the southwest of China suffered a series of droughts. This water project was fully made use of for its water storage and timely and plenty irrigation, therefore, it demonstrated its necessity for the local people and its effectiveness in the drought season. As a result, there were still grain harvests, the luxuriantly green trees on the hills, full of vitality in Baotun village, while in the other areas in the southwest of China the grain reduction appeared, lots of the trees on the hills and mountains died due to the severe drought.

\section{Values of the Water Conservancy Project in Baotun}

Detailed analyses on the values of the cultural heritage should be made to direct tourism plans and tourism development. As a result, we can protect the authenticity and integrality of the cultural heritage, and satisfy the psychological needs of the tourists at the same time. In this way, we can develop the products to pass on the values to the tourists. By studying the values of the cultural heritage of the water project in Baotun, we try to find out the inner connection between the cultural heritage and satisfying of the nostalgic emotion of the tourists, which is the key point for us to make a plan on the tourism development of this cultural heritage.

\subsection{The Scientific Value of the Water Conservancy Project in Baotun}

According to the local natural conditions and the division principle of the fish mouth, the water is made twists and turns so that the farmlands with different heights can be irrigated accordingly and fully. At the same time, the water project has the functions of water supply, flood discharge, drain contamination, waterpower using. It highly embodies the wisdom of the Baotun people who can utilize the natural resources and scientific technology to live a better life. Zhang (2011) thinks that the project has the following characteristics: simple structure, deliberate extension of the dam axis, fully utilization of the bedrock, adoption of the local materials. What is more, the design is scientific, safe, no collapse accidents in over 600 years (Zhang and Pang, 2007). The layout and architectural style of the water conservancy project reflect the Baotun people's idea of using the water resources fairly, and their attitude on nature. That is, all activities of the human beings should be harmonious with nature. The dam types and building materials show the localization of the current scientific technology and the unique architectural aesthetics of the local people (Tan and $\mathrm{Li}$, 2011).

According to Baotun people, the principle of the water project is "a dam, a water of channel and a farmland", which means that Baotun people use the dam to keep water and form a water sump; they build channels to carry water along the contour so that a channel can irrigate the paddy field in the same contour scope. The dam is the key project of controlling water, when the water level is low, the water is kept in the dam; when the water level reaches a certain level, the water is discharged to the farmland from the dam. The outfalls which are set in the different parts of the dam can discharge water at the different water level. They are the main facilities that are used to control the water utilization especially at the rush hours of the irrigation in spring.

The water project in Baotun presents us three main features. First, the design is creative and reasonable. It utilizes the least facilities to obtain the most benefits. Second, the water from the S-shape of the dam top overflows from time to time. It brings multiple engineering benefits, and shows the special technological value of the water project in the countryside. Last, it is the complete channel system that makes the carry-water condition reach the most, and greatly deduces the maintenance cost of the project (Tan and Li, 2011).

\subsection{The Value of Ecological Culture of the Water Conservancy Project in Baotun}

By adequately takes advantage of the flow of the river and the natural topographical conditions, and by fully making use of the creative abilities of the Baotun people, the water conservancy project provides Baotun and neighborhood villages with the rich and happy life for about 640 years long. In the course of over 640 years, the evolution and the dynamic adaptation between the water conservancy project and the surroundings have been giving birth to its unique land utilizing system and land patterns in the Baotun village. The hills and mountains, the forests, and the farmlands are be nourishing, the people are enjoying year-after-year's harvests. 
Therefore a unique man-made ecological system has come into being. All in all, it embodies the specific wisdom of the Baotun people's surviving process in the history, and reflects the harmonious relationship between the Baotun people and the nature.

\subsection{The Aesthetics Value of the Water Conservancy Project in Baotun}

The Baotun ancestors built the water project by referring to the Shuikou garden artistic form, which is popular in the hometown of the south of Anhui province, China and especially, can be seen in the hinterland of the Yunnan-Guizhou Plateau. It is of highly aesthetic value. The Shuikou garden, according to Zhou (2005), was the earliest public garden in China and the earliest embryonic form of the park. The Shuikou garden has multiple values (Wang ,2011), namely, aesthetic value that it melts into the village according to the local natural environment; ecological value that it withstands wind and holds rain and improves environment; architectural value that it organizes the space, constructs the site and enriches the landscape; spiritual value that it meets psychological intention and builds psychological relying. The Shuikou garden belongs to all the villagers: it combines with the farming activities; it merges into the natural mountains and rivers. All kinds of trees can be found here. The landscape of mountains and rivers merges into farmlands; the man-made garden and the village are complementary to each other; the natural environment matches the humanistic activities, all of these reflect the ancient people's idea of "man and nature are in harmony with each other". The farmlands irrigated by the water project and the Shuikou garden together form the beautiful pastoral landscape. What is more, it takes on a new look from season to season. It forms an open garden, which has been cultivating the aesthetic taste of the Baotun people during the past 640 years. It embodies the aesthetic feeling of the Baotun people and provides the Baotun people a poetic inhabiting home.

\subsection{The Value of Public Management Embodied by Maintaining the Water Conservancy Project in Baotun}

The management value embodied by the water conservancy project can be found in the relative rules and regulations about the utilization and preservation of the water project. At the very beginning, the Baotun people laid down the rules and regulations for the whole village and the clan patriarchal system in order to protect the water project, which reflects that the clan social organizations of Chinese countryside validly manage their public affairs. In order to protect the water conservancy facilities and the ecology of river, the Baotun people put up some stone tablets to forbid bad behaviors. At present, there are two stone tablets still remaining in the village, one is called Yima Well Stele, which belongs to the reign of Emperor Zhengde (1506-1521 AD) of the Ming Dynasty; the other is the Big Dam Stele, which dates back to the year of the sixth of the reign of Emperor Xianfeng of the Qing Dynasty. The protective measures were engraved on these two stone tablets, clearly telling the Baotun people about "Do's and Don'ts" regarding the water project. If someone breaks the rule, they will be fined (Peng, 2010). The water consumers assumed to do the maintenance task of the water project; the management of the water project was carried out by the relationship among the farmlands, discharge ditches and dam. During the dry season every winter, under the leadership of the village chief, every household of using water took part in the activity of reinforcing the dam and dredging ditches. The public property of the water project and the private nature of the land were combined by the way of clan patriarchal management, making the water project continue to be used for more than 600 years. Even, up to now it is still working wonderfully. After implementation of collective land ownership in 1949, the management of the water project was undertaken by a special person who was assigned by the production team. After 1978, the land contract policy was carried out in China, the village configuration that supported the project and the using water system has changed a lot, the land management system has been out of line with the public management of the water project. So far, the water project has not been repaired for 30 years, the deposition of sediment is quite serious.

According to the above narration of the history of the management of the water project in Baotun, we can see that, in the self-management mode of the traditional countryside clan patriarchal society, the water project has been kept perfectly and utilized continuously for 600 years. But in the present social system, this management mode does not work any longer, while the proper public management system has not been formed timely. As a result, the maintenance and management are in deficiency. The superiority of the traditional management mode is self-evident.

\section{Tourism Development of the Water Conservancy Project in Baotun}

\subsection{The Principles of Tourism Development of the Water Project}

\subsubsection{Protecting the Agricultural Landscape Characteristics}

If we want to develop tourism based on the water conservancy project in Baotun, first of all, we must protect the characteristics of agricultural views formed by the water project. The characteristics are the core values of the agricultural landscape. What's more, they are the proofs of the existence of the rural features. If the characteristics of agricultural landscape are lost in the tourism development, it means the loss of the rural features, and it means the loss of attraction to the tourists. 
Agricultural landscape refers to various forms of agricultural land formed due to historical or cultural factors, with the rural settlement and its surrounding natural environment as the background and agricultural activities (farming, animal husbandry, etc.) as its base. Agricultural landscape has its own features, which represent the unique man-made ecosystem established over thousands of years of farming activities. They are also land forms based on the geography, climate, soil, hydrology and other environmental factors in rural areas, in combination with unique features of local history, society, economy and culture (Feng and Dai, 2012).

The characteristics of the agricultural landscape in Baotun lie in the features of Tunpu culture and the perfect artificial ecosystem that the water project is in harmonious with the surrounding natural environment. The ecosystem perfectly combines the agricultural production, people's life and ecology to form a whole functional system. The most typical characteristics are the wonderful combination of the water project and the Shuikou garden. The Baotun ancestors not only utilized the river to construct a water project, but also transplanted the hometown's garden art to the new settlement to create a happy life. Furthermore, they expressed the nostalgic feelings to their hometown. In order to strengthen the spiritual connection with their hometown, Baotun people hold a yearly great parading ceremony --raising Wanggong --on the 17th of the first month of the lunar year in the Shuikou garden. By this way, they give the water project unique cultural connotation --- showing the nostalgic feelings to their hometown. In the process of tourism development, we must protect the integrity of the characteristics of the agricultural landscape of the water project. The aim of tourism development should be in accordance with the goal of protecting the characteristics of the water project. At the same time, we can develop the organic agriculture on the farmland irrigated by the water project, construct the organic agriculture base and create famous brands of the green and healthy food in the provincial wide. It will be an effective way to protect the agricultural heritage, and it can add new attractive scenic spot to the cultural tourism. Therefore, more and more tourists will be attracted to experience by themselves, especially those who love healthy food and safe life so deeply.

\subsubsection{Preserving Distinctive Image and Pinpoint Target Market}

With the development of urbanization, people have gradually realized that the countryside cultural landscapes are the most harmonious coexistence between the man and nature, the most optimal human inhabitation environment. So people long for returning to nature and countryside to enjoy the atmosphere of peace and calm and sincere feeling of the country people. In this way, they can divert themselves from the loneliness and alienation. In order to meet the psychological need that the modern people want to experience the traditional lifestyle in the countryside, the rural tourism begins to develop rapidly. Therefore, the tourism development of the water project in Baotun has the distinctive target market, namely, those modern people who are keen on returning to pastoral and nature. By making use of the unique engineering system of the water project, by making use of the characteristics of the integrity of the agricultural production, agricultural life and agricultural ecology, by making use of the "nostalgic feelings" of the modern people, we can try to build a dreamful home for modern people to look for the past good day. The tourism image can be defined like this: the Dujiang Weir of in the hinterland of Yunnan-Guizhou Plateau, the dream beautiful home for the modern people. The theme of the travel can be summarized in the following: "Dujiangyan Dam in the Yun-Gui Plateau; beautiful homeland in the modern people's dream." Besides, we can develop the scientific tour, which can attract many experts, scholars, students and folk amateurs about sociology, folklore, management, engineering to carry out related scientific experiments and studies. In this way, we can exalt the value and fame of the water project, eventually to form the good tourism image. What's more, we can develop the rooting-seeking tour. At first, set up a "partner villages" between Baotun village and Tangyue village, She county, Anhui province. The current Baotun people go to Tangyue village to find their offspring, and Tangyue people come to Baotun village to find their ancestors. In this way, the relatives who were dispersed and departed because of the wars in about 640 years ago will be found again. More and more people in Anhui province and in the southern part of Yangzi River will travel to Baotun village to seek for their ancestors who were sent to war and settled in Guizhou province during the Ming Dynasty. Therefore, the target market will be enlarged greatly with the supplementation of the agricultural products.

\subsubsection{Maintaining the Main Status of the Community}

The water project is the public property of Baotun village, it has a history of more than 600 years when the ancestor, Fubao BAO, who was the first to enter Guizhou province in the Ming dynasty, led clansmen to build the water project. During these 600 years, the project has been brought grain harvests for Baotun villagers; Shuikou garden has connected them with their hometown spiritually. In this way, their self-identity will be confirmed and they themselves have found something to resort to and to thinking about. The water project has long been the public property for all the Baotun villagers, they are the creators and owners of the heritage in the history. So the Baotun villagers' status should be maintained and their rights should be protected in the tourism development. 
The government mainly plays the role of the infrastructure construction and works out and implements the favorable policies, while the enterprises should be prevented from scrambling for profits excessively with Baotun village by some related rules and regulations when they want to do some investment. Priorities should be given to Baotun villagers who have the capacities to run restaurants, accommodations, entertainments, handcrafts, agricultural specialties, tourism performances, etc. In this way, the host position of Baotun villager in the tourism development can be ensured, the life conditions of the villagers can be greatly improved. "The tendency of individualization, independence and stratification of the mass tourism behavior promote the fusion between the tourism space and the community space, the tourism life quality of the tourists is more and more closely tied to that of community residents, Only a livable place is the place suitable for tourism" "From the level of the humanistic ultimate care, tourism development should care for the dignity of the tourists and the living state of the community residents, eventually building the ideal living state of the ideal human poetic dwelling (Peng and Zhang, 2011).

By adopting the concepts of the dynamic conservancy and adaptive management and using the above principles, we can develop tourism of the water project in Baotun; better Baotun people's life. Not only the traditional agricultural culture and the related agricultural ecosystem and biodiversity can be protected, but also we can make it that "the water project becomes the heritage not only of the past but also of the future."

\subsection{The detailed designs on the tourism development of the water conservancy project in Baotun}

\subsubsection{Repairing the whole landscape--the rural cultural landscape fused by the water project and the Shuikou} garden

The water project and the Shuikou garden lie in the front gate of the southern part of Baotun village, where it has the widest view, the most beautiful pastoral scenery, the most harmonious natural environment and humanistic geography. It is the most prominent agricultural cultural landscape; it is also the core scenic spot that attracts the tourists. When designing the tourism planning, we must assure that the whole landscape is not destroyed. At present, some houses have been built by some villagers in this area, which partly broke the wholeness of the landscape. Suggestions should be made that the owners of the house should be persuaded to move out of the area to restore the whole landscape. As to those ditches and channels which have not been cleared in the last 30 years, work should be done to make it clean. The traditional self-maintenance system should be reestablished, for example, the ditches should be cleaned by those who use the water and the irrigations for their plants once a year. The cleaning work can be done every winter when it is a dry season. The maintenance should be made normally by using the materials which can be easily found in the local area. In this way, the ecological environment can be observed. Stone arch bridges or wood bridges should be built so that the villagers and tourists are easy to pass to farm. Stones and wood are used as materials for the bridges in order to preserve the characteristics of the soil and ground in this area. By using the local materials for the constructions, at least three benefits have been made: the water project was constructed right by using of the local material; the nature of preserving the cultural heritage is unchanged; the environment is becoming better and better. A wood pavilion may be built near the watermill as a place for villagers and tourists to rest and enjoy the beautiful view. Meanwhile, the pavilion itself is the scene. There are two hills along the old and new river: one is called "Da Qingshan"("Big Green Hill"), the other is named "Xiao Qingshan" ("Small Green Hill").On the Big Green Hill, the castle is the relic of the Tunpu culture. On the Small Green Hill there is temple called Taiping Temple ("Peace Temple"), which represents the polytheism religion of Baotun villagers. The two hills and the attached architectures like temple, bridges, trees, are the main elements of the Shuikou garden in Baotun. On the top of the two hills the tourists can get a wonderful view of the whole landscape. Walkway can be built on the hill tops; pavilion, attic, stools, made by stones or wood, can be made for the tourists and photographers to do sightseeing and take photos. When we construct the tourist facilities, an important principle is that the raw materials like stones and wood, instead of the cement, can be used in order to prevent the rural feature and the original ecosystem from destroying. By this way we not only maintain the countryside characteristics but also keep the shape and properties of the cultural heritage from changing. The household garbage and production waste in the channels and ditches should be cleaned completely, because the clean surroundings will leave a good impression on the tourists.

Last but not the least, the infrastructure of tourism services cannot be built in the core scenic area. Otherwise, it will destroy the characteristics of the agricultural landscape and the properties of the cultural heritage. It will deviate from the aim of protecting the cultural heritage. Instead, we can choose suitable place outside of the village to construct the service facilities.

\subsubsection{Supplying the affiliated scenes}

We can establish affiliated scenes based on the whole landscape. First, to rebuild Menkoutang (a pond lying in the front of the gate of Baotun village) is to filter the waste water produced by the Baotun villagers. Menkoutang has two functions: one is to clear the domestic sewage. 
All dirty water produced by the villagers firstly was discharged to the pond, the sediment settled and the water was clear in the pond, then the clear water was discharged into the ditches and channels; the other is fire preventing. When the inner part of the village is on fire, the water of the pond is used to put out the fire. For this pond is the nearest water source of the dwelling of the village. Thus when the Baotun ancestors designed the village, they had adopted the effective domestic sewage disposal technique. It is a pity that the pond was filled up to become a road in order to let the car enter the village. Now the dirty water is directly discharged into the ditches without being purified. To plant willows on both sides of rivers is to restore the style and feature in history, Baotun village was originally named the Willow Bay due to those green willows all the year. Several old watermills can be repaired to form the view and rice can be milled for the tourists to buy. Water wheels can be put there for they are used to irrigate the rice field in the farming season. Meanwhile, when it comes to the slack season, the rattling water wheels that go round and round is a peaceful picture of the farming civilization, the tourists can experience the pleasure of farming. Ducks and geese can be kept in the dams and ponds, which create another picture of the farmland. They can also be the healthy and safe food on the tourists' dining table, and be the tourist goods. A lotus pond may be constructed; bamboos can be planted around the pond. Tourists can see another picture in the pond, that is, a reflection of the bamboo in the lotus pond (Peng, 2011).

The historical scenes formed by the water project of Baotun are as follows: appreciating the music from the watermills, retaining flood in the S-shaped dam, watering from the dragon mouth, spiting flow with the fish mouth. The geomantic omen scenes formed by the surroundings of the water project: exploring the geomantic omen in front of the village gate, the conch filling the sea, xiucai (one who passed the imperial examination at the county level in the Ming and Qing dynasties) watching the board publishing exam result, lion and elephant guarding the gate, the top of the mountain connecting the clouds, the jade table ranking, massive supernatural beings casting nets. The scenes formed by the whole village: two cypresses welcoming the guests, lotus pond mirroring the bamboo, the rays of the late sun slanting in the watchtower, the arrays of the Eight Diagrams defending against the enemy, eulogizing the ancient sages in the ancestral temple, meditating the past in the graveyard, the subtle fragrance of the floating. The scenes of the garden: Shuikou garden, the spring foaming, exploring the cave. The scenes of the ethnic customs: exploring the customs in the Miao village, the boulders with leaves, dancing flowers on the Miao hills, etc. These scenes above must be marked, the tour routes and the guiding system be designed to direct the tourists. In addition, the interpretative systems should be built and improved.

\subsubsection{Spreading Folklore Activities}

The Tunbao culture is demonstrated by the folk activities there, of which "raising Wanggong", "shangdafen"on Qingming festival("shangdafen" means that Baotun people clean their ancestor's tomb, such as the tomb of Bao Fubao), "tiaoshen"(an opera danced to the gods. It is also called dixi, which means an opera performed on the land not on the stage. ), the Ox King Festival, and so on.

The activity of "raising Wanggong" is closely related to the Shuikou garden and the water project. On the lunar January 17 every year when it is the birthday of Wanggong, Baotun people hold a big ceremony in which the statue of Wanggong is lifted by people to parade in the Shuikou garden and the farmland irrigated by the water project. By this kind of ritual activity, Baotun people offer sacrifices to gods and ancestors, thanking for their help. Meanwhile, they keep in touch with their hometown spiritually via raising Wanggong statue and parading in the Shuikou garden that is similar to their hometown, and expressing their missing of the hometown. This kind of folk activity can be designed in the tourism programs for the tourists to participate in or to experience by themselves.

"Tiao shen" is held in lunar January and lunar July and lasts for a month respectively. "Tiaoshen" in January is also called "playing in the Spring Festival", with the aim is to pray the grain harvest by sacrificing to gods and ancestors; while "Tiaoshen" in July is also called "Tiao mihuashen", because it is the time for the rice to flower. In the activity, the local villagers are praying to gods and ancestors for the coming rice harvest. In fact, "Tiao shen" becomes a performance of the local people for the tourists. But a problem exists that the tourists find it difficult to follow the performances of the actors and actresses due to the local dialect of their singing and the cultural gap. The way to the problem is to give the tourists a play list with words and explanations on it. In this way, the tourists will fully understand the performance and become a part of it.

"Shangdafen" on Qingming festival in Baotun village is a big sacrificial activity. Generally speaking, there are more than 3000 people participating in the rite. It has been a big event in Baotun village. Many visitors and tourists will take part in the activity willingly to experience by themselves. Lots of advertisements and introduction about the folklore activities can be done to attract more tourists and visitors. In this way, more and more people both at home and abroad will get to know the water project and the customs and the peoples there. 
Other festival activities and their customs like the OX King Festival, the Birthday of the land God, Ghost Festival, the Dragon Festival and the Mid-Autumn Day, etc. can be arranged according to the different seasons. All these folk activities are formed in the process of the long-term farming life of the Baotun people. They are always attractive to the modern tourists, especially those who are with nostalgic feelings.

\subsubsection{Demonstrating Farming life}

Farming life is a laboring activity, which changes with the time and the season. The agricultural landscape originates from the activities of farming, which is the fruit and witness of the integration of nature and agricultural culture in the course of farming. So, the tourism development of the water project should present the daily farming life of Baotun people, such as ploughing, seeding, rice planting, weeding, irrigating, harvesting, river dredging, etc. Watching and even participating in these farming activities make the tourists experience the life lived by their ancestors and the local people, and dispel their nostalgic emotions.

\subsubsection{Advertising the specialties of Baotun}

Once a tourist goes to a new place, he or she will definitely try to taste the local food or specialties there. It is the necessary part of the traveling. By tasting the local special food there, experiencing the true life and culture there, the traveler will experience something completely different from his or her ordinary life (Peng, 2012). Baotun is a typical village of the Tunpu culture, the local specialties should be carefully studied, expanded and strengthened. For example, the local food materials such as the organic rice and vegetables, the roosters and the ducks, the fish and the meat, can be fully used to make specialties by means of the local cooking skills and the local techniques. More and more visitors and tourists, especially those who love green and healthy food, will be attracted greatly. In this way, the beautiful landscapes, the ancient water project, the delicious local food will leave a best impression on the tourists from different parts of China and even the world. Altogether, the people who have been here will have the better understanding of the local culture. Therefore, the food culture, including the raw material preparing, cooking process, food displaying, tasting experiencing, will help the travelers better understand the Baotun culture. The trademarks can be registered to protect the uniqueness and characteristics of the Baotun food culture. Even the brand of special food can be formed to attract the tourists and the connoisseurs as well. The people from the city of Guiyang and Anshun should be attracted to be stable consumers of the local food.

\section{Conclusion}

The water conservancy project of Baotun shows great potential in tourism development to meet the modern people desire for the live in the traditional country lifestyle and to dispel the nostalgic emotion. By analyzing the characteristics of agricultural landscape of the water project of Baotun, working out the detailed principles of developing tourism and specific planning, we hope to give some constructive suggestions for the heritage protection and reasonable utilization. At the same time, we hope to build a good home for the nostalgic modern people by tourism development. They can transiently live poetically in the place, find themselves temporarily experience the past old good days and be far away from the confusing and secular life.

\section{References}

Feng, X. H. and Dai, G. (2012). Characteristics protection of the agricultural landscape in the rural tourism development. Tourism Journal,8,104-111.

Peng, Y. (2011).Tourism Development of Cultural Heritage under Cultural Survival Paradigm--Evidence from Baotun Village of Anshun City in Guizhou Province. Journal of Anshun College,6,1-3.

Peng, Y. (2010).The Ecological Values of the Anshun People . Journal of Anshun College. 1,5-8.

Peng, Y. (2012). On the Construction of the Travel Immigrant Community in Huangguoshu. Journal of Anshun College. 5,8-11.

Peng, Y. and Zhang, B. P. (2011). Gods, Ancestors, Land: the Beliefs of a Tunbao Village. Guizhou Ethnic Studies. 3,59-64.

Tan, X. M. and Li, Y.P. (2011). The Conservation of the Ancient Rural Water Project - An Outstanding Example of the Agricultural Landscape Conservation . China Cultural Heritage. 6,50-55.

Wang, P. (2011). The Shuikou Park in Huizhou Villages. Anhui Architecture. 3,53-54.

Zhang, W.D. (2011). Baotun Rural Water Restoration Project Was Conferred to the Award of Excellence by the AsiaPacific Heritage Commission. China Water Resources, 2011, 10-18:01.

Zhang, W.D. and Pang, Y.B. (2007) . Investigation of 600 Years of Water Use in Baotun . China Water Conservancy. 12,53-54.

Zhou, J.C. (2005). The Design History of the Shuikou Park . Technology and Market (Gardening). 3,41-43. 